\title{
Surgical treatment of sternum comminuted fracture with memory alloy embracing fixator
}

\author{
Shun Xu ${ }^{1,2}$, Jie Zhu ${ }^{1}$, Qi Yu ${ }^{1}$, Leilei Peng ${ }^{1}$, Yu Tao ${ }^{1}$, Shengbo Qi ${ }^{1}$, Hao Han ${ }^{1}$, Yongjing Liu ${ }^{1}$ \\ ${ }^{1}$ Department of Thoracic Surgery, The 901st Hospital of the Joint Logistics Support Force of PLA, Hefei, China; ${ }^{2}$ Department of Surgery, The \\ Affiliated Jiangning Hospital of Nanjing Medical University, Nanjing, China \\ Contributions: (I) Conception design: S Xu; (II) Administrative support: Y Liu; (III) Provision of study materials or patients: J Zhu, Q Yu; (IV) \\ Collection and assembly of data: L Peng, Y Tao; (V) Data analysis and interpretation: S Qi, H Han; (VI) Manuscript writing: All authors; (VII) Final \\ approval of manuscript: All authors. \\ Correspondence to: Yongjing Liu. Department of Thoracic Surgery, The 901st Hospital of the Joint Logistics Support Force of PLA, Hefei 230031, \\ China. Email: yongjingliu@163.com.
}

Background: Sternal fracture can result from multiple types of severe chest trauma and carries significant risk. Surgical fixation is an effective method for sternal fracture.

Methods: The clinical data of patients with sternal fractures who presented to our hospital between August 2016 and July 2019 were collected. The 42 patients were divided into three groups, with 15 patients treated by internal fixation with NI-TI memory alloy embracing fixator, 10 patients receiving steel wire fixation, and 17 who received non-surgical treatment and who was designated as a control (conservative) group. Differences in clinical indices included the duration of surgery, blood loss, hospitalization, wound healing, hospitalization expenses, VAS scores, and patient satisfaction scores between the three groups was compared. The analysis of variance and t-test were used for quantitative variables, which were approximately normally distributed. Dichotomous data were compared used Pearson $\chi^{2}$ or Fisher's exact test, and a P value less than 0.05 was considered as statistically significant.

Results: All patients were cured, and there were no significant differences in general clinical features between the three groups $(\mathrm{P}>0.05)$. Thoracic deformity in the surgical groups was corrected anatomically and received better pain scores, while patients in the NI-TI memory alloy embracing fixator group showed advantages of bleeding and patient satisfaction $(\mathrm{P}<0.05)$.

Conclusions: Operative treatment for a sternal fracture is safe, effective and can quickly restore the stability of the thorax. Memory alloy embracing fixator is markedly superior to other fixator materials.

Keywords: Sternal fracture; operations fixation; memory alloy embracing fixator; advantages

Submitted Dec 28, 2020. Accepted for publication Feb 26, 2021.

doi: $10.21037 /$ jtd-20-3603

View this article at: http://dx.doi.org/10.21037/jtd-20-3603

\section{Introduction}

Sternal fractures are a rare form of chest injury and are mainly due to a violent force applied to the thorax's sternum area or crush injury (1). Traffic accidents, high fall injuries, and spinal hyperflexion injuries are the main causes, and severe sternal fractures are often associated with lung injury or heart trauma, leading to respiratory failure and shock (2-4). Sternal fractures are usually not difficult to diagnose through a detailed medical history, CT scan, and clinical symptoms $(5,6)$, and the most common fracture site is the gladiolus or gladiomanurical junction (7).

The treatment method sternal fracture can include conservative medical treatment and surgical operation, largely depending on the presence of fracture shifts or complications (8). Stable fractures with little or no displacement can be treated with manual reduction and analgesia treatment (9). However, for patients with serious displacement or a combination of injuries to organs in 
the pleuroperitoneal cavity, surgical treatment is often necessary (10). However, for some patients with simple sternal fractures and minimal displacement, there were two therapeutic options can be selected (11).

This article aims to compare the effectiveness of three treatments for patients with sternal fracture.

We present the following article in accordance with the STROBE reporting checklist (available at http://dx.doi. org/10.21037/jtd-20-3603).

\section{Methods}

\section{Sternal fractures of patients}

We collected the detailed clinical data of 81 patients who received sternal fracture treatment in our hospital between August 2016 to July 2019. Thirty-nine patients with either undisplaced sternal fracture, internal bleeding, or multiple severe injuries were excluded from the study. The remaining 42 patients with fracture and displacement were included, and of these, 25 patients received internal fixation treatment, and 17 were selected for non-operative treatment (non-operative treatment group). In patients receiving surgery, 10 were treated with fixed steel wire (steel wire fixed treatment group), and 15 were fixed with memory alloy (memory alloy fixed treatment group). It is important to note that the displacement degrees of fractures were different in the operation group and conservative groups. Three researchers collected clinical data independently to reduce bias. The study was conducted in accordance with the Declaration of Helsinki (as revised in 2013). This study was approved by the ethics committee of the 901st Hospital of the Joint Logistics Support Force of PLA (2019L06). The informed consent from each patient or the individual patient's family was waived because there were no new interventions for the patients and the information was anonymized.

\section{Method of surgical treatment}

All patients underwent a CT scan and three-dimensional reconstruction of the sternum before surgery. Three patients had multiple rib fractures that were fixed at a single stage. Of the 25 surgical patients, four had hemopneumothorax and were initially treated with closed thoracic drainage using a thoracoscope placed in the thoracic drainage tube orifice. Surgical approaches were based on the fracture sites and complications. In the memory alloy fixed treatment group, all 15 patients underwent general anesthesia by tracheal intubation with the thoracodorsal region elevated for better exposure. A median sternotomy was used, and a left-sided chest wall united incision was used for two patients with a severe rib fracture. The skin and subcutaneous tissue were incised first, then using imaging data, the fracture sides were opposed, and the periosteum incised along the fracture line. Separation of tissue was minimized when the fracture ends were exposed to preserve the periosteal blood supply and bone perfusion to facilitate healing. A reduction clamp and towel forceps were used, and a suitable nitinol memory alloy embracing fixator to place on the fracture was then placed in ice water to obtain the correct shape. The shaped fixator was then placed into the fracture sides, the four arms of the embracing fixator located in the superior and inferior costal fovea, then $40-50{ }^{\circ} \mathrm{C}$ water was used to hot compress the fixator to make it shrink. Standard wound observation and anti-infection treatment after surgery were followed for one to three days according to patients' condition.

To accurately localize the surgical region, all patients fixed with steel wire first underwent CT or X-ray scan before a routine median sternotomy was performed in all cases except one. Two holes were drilled at each end of the fractured sternum, a specialized wire then threaded through the holes, and a steel wire fixed and tightened to a suitable pressure. One patient with severe rib fractures and obvious pleural effusion was treated with combined anterior lateral incision thoracotomy.

\section{Non-operative treatment group}

Non-operative therapy was provided to 17 patients. In the 10 patients with no obvious displacement, an adopted supine or semi-reclining position was established, and a thin pillow was used to raise the backside while the chest was secured with a chest strap. In the seven patients receiving manipulative reduction treatment, the supine position was adopted on a hard bed with the backside raised. Local anesthesia was used to alleviate pain, and the broken end of the fracture was manipulated in timing with expiratory movement. A "click" sound indicated successful reduction, which was confirmed by an X-ray scan. Treatment in the conservative therapy group included analgesia treatment, oxygen, antibiotics, and aerosol inhalation.

\section{Main outcome measures and statistical analysis}

Clinical data were collected, and comparative analysis was 


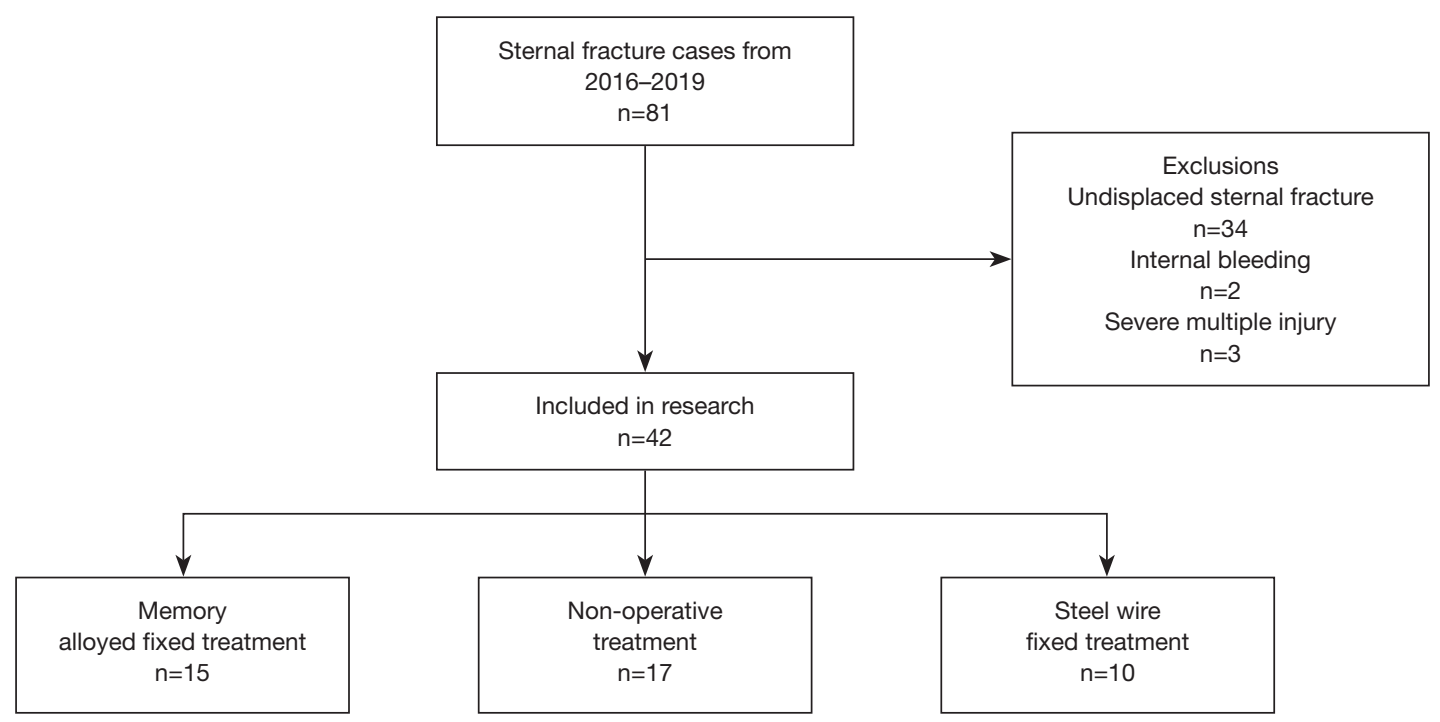

Figure 1 Patient selection program.

conducted. We extracted the main indicators, including surgery duration, blood loss, hospitalization, wound healing, hospitalization expenses, and follow-up information, including fracture healing, pain experience, and patient satisfaction scores, in the three groups. We also recorded the reasons for incomplete follow-up. The variance and $t$ test analysis were used for quantitative variables that were approximately normally distributed, and dichotomous data were compared used Pearson $\chi^{2}$ or Fisher's exact test. All statistical analyses were performed using SPSS software 22.0 version, and $\mathrm{P}<0.05$ was considered to indicate a statistical difference.

\section{Results}

\section{General clinical index of the three groups}

The patient selection diagram is shown in Figure 1. A total of 42 sternal fracture patients were studied, and these were divided into three groups. The age range was 14 to 82 years, the median age was 39 years, and there were 28 males and 14 females. The general clinical characteristics of patients in the three groups are shown in Table 1. The general clinical index differences between the three groups showed no statistical significance $(\mathrm{P}<0.05)$.

\section{Objective standards during and after the operation}

Surgical treatment was selected for 25 patients. The operations were finished smoothly with no deaths, the mean duration of surgery in the memory alloy fixed treatment group was $99.07 \pm 30.09$ minutes, and the longest operation was a patient suffering from multiple-rib fractures and pulmonary contusion. All fracture deformities were corrected, and paradoxical breathing disappeared after surgery. In the steel wire fixed group, the mean procedure time was $83.60 \pm 12.79$ minutes. Two patients with serious chest trauma were admitted to the Surgical Intensive Care Unit after surgery and smoothly returned to the general ward the next day. All patients underwent bedside X-ray examination after surgery (Figure 2). The clinical index of surgery duration, blood loss, hospital stays, wound healing, hospitalization expenses, and follow-up information are shown in Table 2.

\section{Non-operative treatment conditions}

All 17 patients in the non-operative group smoothly recovered and were discharged. Manipulative reduction treatment was applied to seven patients, and no subsequent displacement was observed on a chest CT scan. The clinical index indicated that patients treated with nonsurgical therapy paid fewer hospitalization costs than those undergoing surgery and avoided surgical incision infection risk. However, two patients developed delayed-type mediastinal hematoma as seen on chest CT scan during the treatment, and one experienced pulmonary infection because they refused to cough and expectorate. The visual analog scales (VAS) pain scores of all three groups 
Table 1 Clinical index of patients

\begin{tabular}{|c|c|c|c|c|c|}
\hline Clinical index & \multicolumn{3}{|c|}{ Number of cases } & $t / \chi^{2}$ & $\mathrm{P}$ \\
\hline Sex & & & & 0.861 & 0.650 \\
\hline Male & $10(23.8 \%)$ & $13(30.6 \%)$ & $6(14.3 \%)$ & & \\
\hline Female & 5 (11.9\%) & $4(9.5 \%)$ & $4(9.5 \%)$ & & \\
\hline$\geq 60$ years & $4(9.5 \%)$ & $7(16.7 \%)$ & $2(4.8 \%)$ & & \\
\hline$<60$ years & $11(26.2 \%)$ & $10(23.8 \%)$ & $8(19.0)$ & & \\
\hline BMI & & & & 0.400 & 0.819 \\
\hline$\geq 24$ & $5(11.9 \%)$ & $7(16.7 \%)$ & $3(7.1 \%)$ & & \\
\hline Underlying disease & $3(7.1 \%)$ & $5(11.9 \%)$ & $2(4.8 \%)$ & & \\
\hline Healthy & $12(28.6 \%)$ & $12(28.6)$ & 8 (19.0\%) & & \\
\hline
\end{tabular}

are shown in Table 3. This reveals that the non-operative treatment group obtained relatively worse scores than the surgical group $(\mathrm{P}<0.05)$.

\section{Follow-up information}

The 42 patients were followed up for $(12 \pm 2)$ months (range, 10-15 months), and no graft rejection or sternal infection was reported. Although one patient in the steel wire treatment group reported pain when exercising their chest, a CT scan showed satisfactory healing. Two patients who experienced mediastinal hematoma in the conservative treatment group returned to our hospital one month after their initial admission, and a chest CT scan showed the hematoma size had obviously shrunk. While there were three patients with deformed healing in the conservative treatment group, none reported significant disruption to their daily activities. Patients' subjective assessment was further assessed using patient satisfaction scores, with the highest (best outcome) score being 100 points. After 3 months, 6 months, and 12 months from the day of discharge, patients' satisfaction scores are shown in Table 4. While in the first 6 months, the was no significant difference in satisfaction between the three groups, the scores in the memory alloy fixed treatment group were superior to the other two groups in the most recent follow-up.

\section{Discussion}

The sternum is a relatively hard flat bone located in the middle of the chest, comprised of the manubrium, gladiolus, and xiphoid segments $(12,13)$. Most sternal fractures are caused by direct force, the fracture site is always located in the body or manubrium, and the fracture line is usually transverse extension (14). Multi-slice spiral $\mathrm{CT}$ and $3 \mathrm{D}$ reconstruction techniques have made the sternal fracture diagnosis no longer difficult $(15,16)$. While simple undisplaced fractures usually do not require special medical treatment, displaced fractures or those associated with serious chest visceral injury should receive appropriate treatment. The retrosternal space is adjacent to the anterior mediastinum, and high energy violence applied to the anterior chest wall carries a high association with a serious injury, such as cardiac and aorta contusion, multiple rib fractures, and pulmonary contusion $(17,18)$. As these injuries can cause massive bleeding, respiratory failure, and a series of pathophysiological changes (19), which threatens patients' lives, providing the correct treatment for a displaced sternal fracture is critical.

Therapies for sternal fracture include conservative and surgical treatment, and most clinicians believe that patients with undisplaced sternal fractures can be treated with conservative medical methods. In a 17 -year follow-up study, Molina reported that surgical treatment for undisplaced 

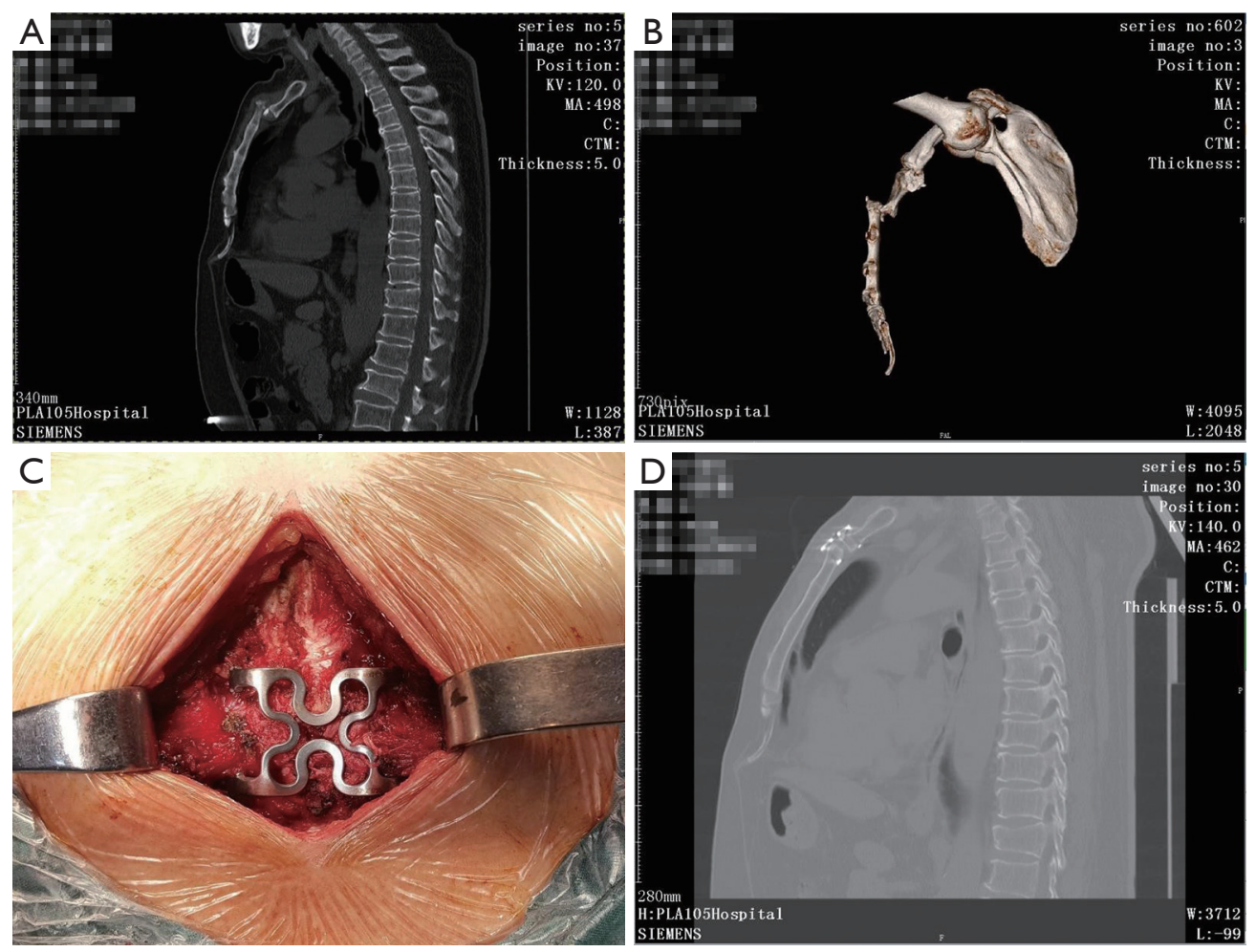

Figure 2 Clinical data before and after surgery. (A) CT scan for a patient with sternal fractures before fixation; (B) 3D reconstruction for the fractured ribs before surgery; (C) memory alloy plate used for surgery; (D) CT scan of patient after surgery.

Table 2 Clinical outcome of the two surgery groups

\begin{tabular}{lcccccc}
\hline Group & $\begin{array}{c}\text { Duration of } \\
\text { operation }(\mathrm{min})\end{array}$ & $\begin{array}{c}\text { Blood loss of } \\
\text { surgery }(\mathrm{mL})\end{array}$ & $\begin{array}{c}\text { Hospital stays } \\
(\text { days })\end{array}$ & $\begin{array}{c}\text { Hospitalization } \\
\text { expenses }(¥)\end{array}$ & \multicolumn{2}{c}{ Wound infection } \\
\cline { 5 - 6 } Memory alloyed fixed & $99.07 \pm 30.09$ & $40.67 \pm 31.50$ & $9.33 \pm 2.50$ & $18,417 \pm 3,267$ & $2(13.3 \%)$ & $13(86.7 \%)$ \\
Steel wire fixed & $83.60 \pm 12.79$ & $91.00 \pm 28.17$ & $9.30 \pm 2.58$ & $18,084 \pm 2,296$ & $1(10 \%)$ & $9(90 \%)$ \\
Statistics & 1.527 & -4.08 & 0.032 & 0.279 & $\chi^{2}=1.00$ \\
P value & 0.140 & $<0.01$ & 0.975 & 0.783 & $P=0.654$ \\
\hline
\end{tabular}

sternal fracture was successful (20). Our daily clinical work has found that both medical and surgical treatment for an isolated sternal fracture is possible, and each has its advantages. Accurately determining surgical intervention indications is very important as cardiopulmonary and mediastinal complications can deteriorate rapidly (21). In our trauma center, the indications of surgery for sternal fracture include flail chest, open sternal fracture, cases where the end of the fracture compresses the mediastinal organs, or organ damage has occurred comminuted sternal fracture affects the stability of the chest.
Non-operative treatment for sternal fracture includes external fixation, analgesia treatment, and intravenous fluids to maintain electrolyte balance and manipulative reduction. Through observation and analysis of the clinical data of all 17 patients in the conservative treatment group, we found that the stability of the sternum was related to the fractured site (22), with fractures in the upper sternum usually relating to poor stability. Manipulative reduction therapy and a fixed chest belt were applied in two patients, but mildly paradoxical breathing still appeared. Surgery to fix the broken end of the fracture and restore the chest's 
Table 3 The VAS scores for the time discharged between the three groups

\begin{tabular}{lccc}
\hline Group & Cases & VAS & F \\
\hline Memory alloy fixed group & 15 & $2.53 \pm 1.51$ & \\
Non-operative treatment group & 17 & $2.40 \pm 1.35$ & 6.185 \\
Steel wire fixed group & 10 & $4.12 \pm 1.54$ & 0.005 \\
\hline
\end{tabular}

VAS, visual analog scale.

Table 4 Patients satisfaction scores of the three groups

\begin{tabular}{|c|c|c|c|c|c|}
\hline Satisfaction scores & $\begin{array}{c}\text { Memory alloyed fixed } \\
\text { group }\end{array}$ & Steel wire fixed group & $\begin{array}{l}\text { Non-operative } \\
\text { treatment group }\end{array}$ & $\mathrm{F}$ & $\mathrm{P}$ \\
\hline Three months from discharge & $88.40 \pm 5.95$ & $88.30 \pm 4.90$ & $86.41 \pm 5.32$ & 0.645 & 0.530 \\
\hline Six months from discharge & $92.73 \pm 4.59$ & $92.40 \pm 4.20$ & $90.24 \pm 4.32$ & 1.484 & 0.239 \\
\hline Twelve months from discharge & $95.53 \pm 3.85$ & $91.40 \pm 4.35$ & $91.18 \pm 4.41$ & 6.833 & 0.003 \\
\hline
\end{tabular}

stability was used in a broader range of patients. Also, the complications of sternal fracture could be treated during surgery. Severe rib fractures were seen in three patients, and they received internal fixation. A preoperative CT scan helps determine the precise location for a surgical approach and provides a reference for selecting surgical procedures (23). For patients with great vessel trauma, surgical hemostasis and repair should be repaired first, and the sternum attended to in the second stage of the operation.

Internal fixation materials for sternal fractures mainly include steel wire fixation, memory alloy fixator treatment, and titanium plate fixation, and in our hospital, steel wire fixator and memory alloy fixator are often used. Although internal plate fixation is relatively reliable, it requires drilling into the sternum, increasing the risk of damage to retrosternal organs and requiring a second operation to remove the plate. Steel wire fixation is a traditional surgical procedure (24), but the operative space is small, threading the steel wire is not easy, and dissection of the periosteum can affect the sternal blood supply. Also, steel wire involves a cutting force on the sternum, and the treatment effect is generally poor for irregular or comminuted fractures. While in our study, only one patient was treated with mild steel wire displacement, clinicians have also reported good results using steel wire with a needle similar to that used in cardiac surgery to fix the fracture (25). Nickel-titanium memory alloy embracing fixator is a new type of material combining sensing with actuation (26). It is widely used for sternal fracture in our medical center and has favorable histocompatibility, excellent corrosion resistance, and self- pressurized function. Memory alloy embracing fixation is simple, and blood loss during surgery was less compared with the steel wire treatment group in our study. We did not incise the periosteum during memory alloy embracing fixator treatment procedures, as the embracing arm can maintain the stability of fracture through the gripping force to the costal fovea, leaving no need to dissect the retrosternal space. These properties result in patients obtaining a better medical experience when treated with memory alloy embracing fixator, as shown in this group's superior VAS scores. However, some disadvantages to this method exist, including the risk that the fixator's shape would return to its original form with a change of temperature, and the changed fixator may not fit the sternum. Also, due to the fixator's volume, the cosmetic appearance of the anterior chest wall is altered in some patients, the fixator is more expensive than wiring, and the reversibility of the memory effect may be insufficient.

Surgery for sternal fracture is becoming minimally invasive and more accurate as medical technology improves $(1,27)$. MSCT was widely used for diagnosis and treatment in the earlier period of injuries in our trauma center, and large amounts of data were collected on its use. MSCT multiplane reformation (MPR) can provide sagittal, coronal, and oblique reconstruction information, and three-dimensional CT reconstruction can clearly show the details of trauma and the 3D spatial relationship of fractures. Reconstruction technology also takes a short time, is easy to operate, and reduced the miss rate for nonobvious displaced fractures in one study (28). In our study, 
all 42 patients received MSCT scan and 3D reconstruction, and the preoperative and intraoperative localization were consistent. Various imaging examination data also play a significant role in follow-up appointments and reexaminations. For patients with sternal fracture associated with other chest injuries, corresponding treatment is usually required. In this study, we focused on associated injuries that required surgical treatment. Four patients received video-associated thoracoscope (VATS) explorations treatment, which allowed observation of the thorax and easy cleaning of blood clots, completion of lung rupture repair, and observation of multiple rib fractures. Three patients required rib fracture fixed surgery in our study, using MSCT reconstruction and VATS technology made the surgery more precise and involved minimal invasion.

The early and accurate diagnosis of suspected sternal fracture following trauma is very important, and the application of timely and correct clinical treatment is the key requirement for obtaining successful outcomes (29). Conservative therapy is also an acceptable treatment for undisplaced sternum fracture patients and is especially useful in patients who do not wish to undergo internal fixation (30). Our research used a nickel-titanium memory alloy fixator for 15 patients with displaced sternal fractures and achieved a good therapeutic effect. The Ni-Ti memory ally fixator is an ideal internal fixation material that can relieve pain effectively after surgery, mobilizes patients more quickly, and reduces pulmonary complications. However, in the future, a more absorbable material with stronger plasticity which can provide a more precise fit is needed better to suit individual patients' needs (31). The successful use of autologous stem cells for sternal reconstruction has also been reported and may hold future promise in treating sternal fracture (32).

The limitations to this study are its small sample size and limited follow-up period. Studies with larger sample size and longer follow-up periods are required to confirm the results.

\section{Acknowledgments}

Funding: This work was supported by the open fund of the State Key Laboratory of Trauma, Burn and Compound injury of Army Military Medical University.

\section{Footnote}

Reporting Checklist: The authors have completed the
STROBE reporting checklist. Available at http://dx.doi. org/10.21037/jtd-20-3603

Data Sharing Statement: Available at http://dx.doi. org/10.21037/jtd-20-3603

Peer Review File: Available at http://dx.doi.org/10.21037/jtd20-3603

Conflicts of Interest: All authors have completed the ICMJE uniform disclosure form (available at http://dx.doi. org/10.21037/jtd-20-3603). All authors report grants from the State Key Laboratory of Trauma, Burn and Compound injury of Army Military Medical University, during the conduct of the study.

Ethical Statement: The authors are accountable for all aspects of the work in ensuring that questions related to the accuracy or integrity of any part of the work are appropriately investigated and resolved. The study was conducted in accordance with the Declaration of Helsinki (as revised in 2013). This study was approved by the ethics committee of the 901st Hospital of the Joint Logistics Support Force of PLA (2019L06). The informed consent from each patient or the individual patient's family was waived because there were no new interventions for the patients and the information was anonymized.

Open Access Statement: This is an Open Access article distributed in accordance with the Creative Commons Attribution-NonCommercial-NoDerivs 4.0 International License (CC BY-NC-ND 4.0), which permits the noncommercial replication and distribution of the article with the strict proviso that no changes or edits are made and the original work is properly cited (including links to both the formal publication through the relevant DOI and the license). See: https://creativecommons.org/licenses/by-nc-nd/4.0/.

\section{References}

1. Klei DS, de Jong MB, Öner FC, et al. Current treatment and outcomes of traumatic sternal fractures-a systematic review. Int Orthop 2019;43:1455-64.

2. Harston A, Roberts C. Fixation of sternal fractures: a systematic review. J Trauma 2011;71:1875-9.

3. Schulz-Drost S, Krinner S, Langenbach A, et al. The Operative Management of Flail Chest Injuries with Concomitant Sternal Fracture. Chirurgia (Bucur) 
2017;112:573-93.

4. Oyetunji TA, Jackson HT, Obirieze AC, et al. Associated injuries in traumatic sternal fractures: a review of the National Trauma Data Bank. Am Surg 2013;79:702-5.

5. Metaxas EK, Condilis N, Tzatzadakis N, et al. Sternal fracture with or without associated injuries. Assessment of the difference in the diagnosis, management and complications. Eighteen years of experience. Ann Ital Chir 2006;77:379-83.

6. Kim EY, Yang HJ, Sung YM, et al. Sternal fracture in the emergency department: diagnostic value of multidetector CT with sagittal and coronal reconstruction images. Eur J Radiol 2012;81:e708-11.

7. Kälicke T, Frangen TM, Müller EJ. et al. Traumatic manubriosternal dislocation. Arch Orthop Trauma Surg 2006;126:411-6.

8. Schulz-Drost S, Oppel P, Grupp S, et al. Surgical fixation of sternal fractures: preoperative planning and a safe surgical technique using locked titanium plates and depth limited drilling. J Vis Exp 2015;5:e52124.

9. Potaris K, Gakidis J, Mihos P, et al. Management of sternal fractures: 239 cases. Asian Cardiovasc Thorac Ann 2002;10:145-9.

10. Salehi F, Niusha S, Saghebi SR, et al. Technical Details of Surgical Treatment of a Severely Displaced Sternal Fracture. Tanaffos 2019;18:365-8.

11. Schulz-Drost S, Krinner S, Oppel P, et al. Fractures of the manubrium sterni: treatment options and a possible classification of different types of fractures. J Thorac Dis 2018;10:1394-405.

12. Saraf A, Kanchan T, Krishan K, et al. Estimation of stature from sternum - Exploring the quadratic models. J Forensic Leg Med 2018;58:9-13.

13. Singh J, Pathak RK, Chavali KH. Skeletal height estimation from regression analysis of sternal lengths in a Northwest Indian population of Chandigarh region: a postmortem study. Forensic Sci Int 2011;206:211.e1-8.

14. Zeitani J, Penta de Peppo A, Moscarelli M, et al. Influence of sternal size and inadvertent paramedian sternotomy on stability of the closure site: a clinical and mechanical study. J Thorac Cardiovasc Surg 2006;132:38-42.

15. Shao Y, Huang P, Li ZD, et al. Establishment of a 3D finite element model of human thoracic cage and biomechanical analysis. Fa Yi Xue Za Zhi 2013;29:81-5.

16. Kashiwagi Y, Sasakawa T, Tampo A, et al. Computed tomography findings of complications resulting from cardiopulmonary resuscitation. Resuscitation 2015;88:86-91.

17. Hammer MM, Raptis DA, Cummings KW, et al. Imaging in blunt cardiac injury: Computed tomographic findings in cardiac contusion and associated injuries. Injury 2016;47:1025-30.

18. Al-Thani H, Jabbour G, El-Menyar A, et al. Traumatic sternal injury in patients with rib fracture: A single-center experience. Int J Crit Illn Inj Sci 2019;9:75-81.

19. Schulz-Drost S, Ekkernkamp A, Stengel D. Epidemiology, Injury Entities and Treatment Practice for Chest Wall Injuries: Current Scientific Knowledge and Treatment Recommendations. Unfallchirurg 2018;121:605-14.

20. Molina JE. Evaluation and operative technique to repair isolated sternal fractures. J Thorac Cardiovasc Surg 2005;130:445-8.

21. Kalberer N, Frima H, Michelitsch C, et al. Osteosynthesis of sternal fractures with double locking compression plate fixation: a retrospective cohort study. Eur J Orthop Surg Traumatol 2020;30:75-81.

22. Huang Z, Chen F, Huang J, et al. Treatment of middlesuper thoracic fractures associated with the sternum fracture. Int J Clin Exp Med 2015;8:9751-7.

23. Scheyerer MJ, Zimmermann SM, Bouaicha S, et al. Location of sternal fractures as a possible marker for associated injuries. Emerg Med Int 2013;2013:407589.

24. Divisi D, Di Leonardo G, Crisci R. Surgical management of traumatic isolated sternal fracture and manubriosternal dislocation. J Trauma Acute Care Surg 2013;75:824-9.

25. Yang HD, Chi F, Wang J, et al. Steel wire internal fixing sternal fractures through midsternal incision approach: A clinical experience of 16 patients. Chin J Clin Thorac Cardiovasc Surg 2016;23:636-8.

26. Xiong M, Hu W, Lou Q, et al. Efficacy of nickeltitanium memory alloy in the treatment of multiple rib fracture combined with sternal fracture. Exp Ther Med 2019;18:537-42.

27. Xie ZX, Zhou XT, Zhang DS, et al. Minimally invasive plate osteosynthesis for the treatment of sternal fracture in the lower chest: a case report. J Int Med Res 2019;47:4033-8.

28. Petrović K, Turkalj I, Stojanović S, et al. Blunt trauma of bone structures of the chest-computed tomography vs multidetector computed tomography. Vojnosanit Pregl 2013;70:757-61.

29. Davis SNP, Delaney JS, Robichaud L. An unusual cause of chest pain: Exercise induced sternal fracture in a young man. Am J Emerg Med 2020;23:S0735-6757(20)3038930382.

30. Broadhurst J, Moorjani N, Ohri S. Traumatic fracture of nitinol thermoreactive sternal clips. Interact Cardiovasc 
Thorac Surg 2010;10:465-6.

31. Nolasco-de la Rosa AL, Mosiñoz-Montes R, MatehualaGarcía J, et al. Unstable thorax fixation with bioabsorbable plates and screws. Presentation of some cases. Cir Cir

Cite this article as: $\mathrm{Xu} \mathrm{S,} \mathrm{Zhu} \mathrm{J,} \mathrm{Yu} \mathrm{Q,} \mathrm{Peng} \mathrm{L,} \mathrm{Tao} \mathrm{Y,} \mathrm{Qi}$ S, Han H, Liu Y. Surgical treatment of sternum comminuted fracture with memory alloy embracing fixator. J Thorac Dis 2021;13(4):2194-2202. doi: 10.21037/jtd-20-3603
2015;83:23-8.

32. Khalpey Z, Marsh KM, Ferng A, et al. First in Man: Sternal Reconstruction with Autologous Stem Cells. ASAIO J 2015;61:e31-2. 